\title{
Climate Change Awareness and Decision on Adaptation Measures by Livestock Farmers in South Africa
}

\author{
B. Mandleni \& F.D.K. Anim \\ University of South Africa, College of Agriculture \& Environmental Sciences \\ Department of Agriculture and Animal Health, Florida Campus \\ Private Bag X6 Florida 1710, South Africa \\ Tel: 11-471-2252 E-mail: mandlb@unisa.ac.za
}

Received: November 15, 2010 Accepted: November 30, 2010 doi:10.5539/jas.v3n3p258

\begin{abstract}
This paper investigated the extent of awareness of climate change by livestock farmers in the Eastern Cape Province of South Africa. It further explored the choice of adaptation measures that were followed and factors that affected adaption measures. The results indicated that marital status, level of education, formal extension, temperatures and the way in which land was acquired, significantly affected awareness of climate change. Variables that significantly affected adaptation selections were gender, formal extension, information received about climate change, temperatures and the way in which land was acquired. The study suggested that the positive and significant variables that affected awareness and adaptation measures by livestock farmers be considered when awareness and adaptation strategies are implemented.
\end{abstract}

Keywords: Climate change awareness, Heckman's two step probit model, Decisions to adapt

\section{Introduction}

Awareness of climate change in many studies has been of great concern. Adaptation measures to climate change have often been a way to pursue for many African countries in order to reduce the negative effects. A consensus has emerged that developing countries are more vulnerable to climate change than developed countries because of the predominance of agriculture in their economies and scarcity of capital for adaptation measures, Fischer $e t$ al. (2005). South Africa, being a developing country with agriculture dominating other sectors of the economy, is highly likely to be vulnerable to climate change (Gbetibouo and Hassan, 2005). Predictions about climate change in South Africa in a study conducted in 2002 indicated that certain species of animals are likely to become extinct as a result of climate change (Turpie et al. 2002). Eastern Cape Province whose economy is mainly agriculture is also most likely to be vulnerable to climate change. This has called for this study that seeks to establish whether livestock farmers in the Eastern Cape were aware of climate change and the adaptation measures that they opted for in order to curb the negative effects of climate change between 2005 and 2009.

The objectives of this study was firstly to establish the extent of awareness of climate change in the area of study and to select livestock producers that were aware of climate change from a pooled sample of 250 respondents. Secondly, the objective was to isolate those livestock farmers that adapted to climate change from the group that was aware of climate change and to identify adaptation measures that they adopted.

The rest of the paper is organised as follows: In section 2 the method that was used to collect data is outlined. In section 3, the empirical model that was employed is specified. Section 4 presents results in the form of descriptive statistics followed by Heckman's two step probit model results. Section 5 discusses the results and section 6 summarises and concludes the paper.

\section{Data collection}

This study was based on a cross-sectional household survey data collected from 250 household heads during the 2005-2009 farming season in three district municipalities in the Eastern Cape of South Africa namely: Amathole, Chris Hani and OR Tambo. The 250 households surveyed were from the three selected district municipalities based on representative agro-ecological zones and livestock farming systems in each municipality. The sampled districts were selected purposefully to cover uniform or homogeneous characteristics of the three areas, namely: agro ecological zones, intensity of livestock (cattle and sheep) farming activities, average annual rainfall and household characteristics. The 250 households were proportionally selected according to the information on 
household sizes given by the Department of Agriculture and Rural Development office. The choice of exogenous variables used in the analysis was guided by available literature and economic theory.

\section{Empirical model}

The awareness of livestock farmers about climate change and the decision to select adaption measures was considered to be a two-stage process. The first stage was whether livestock farmers were aware of climate change or not. The second stage involved whether livestock farmers adapted to climate change after being aware and selecting some adaptation measures. The second stage, called the "outcome" stage was considered a sub-sample of the first stage, the "selection" stage. Since the outcome stage was a sub-sample of the selection stage, it was likely that the outcome stage sub-sample will be non-random and different from those farmers who did not become aware of climate change in the full sample. A sample selection bias was then created which was corrected by the maximum likelihood Heckman's two-step or Heckit selection procedure (Heckman, 1979).

The Heckman two-step estimation is a way of estimating treatment effects when the treated sample is self-selected. The application of this model in this study was to estimate the determinants of an individual livestock farmer's decision to select adaptation. The first step was to create a model of farmers who were aware of climate change, and then given that model, the outcomes (adaptation) was modeled (Deressa et. al., 2009).

Let $\prod_{i j e}$ be a vector of observations of the size of issue for the $i^{\text {th }}$ group of livestock farmers with a $j^{\text {th }}$ form of awareness and non-awareness of climate change, and let $\mathrm{X}_{i j}$ be a vector of observations on measurable socio-economic characteristics and other associated variables associated with the $j^{\text {th }}$ state of awareness. Thus we can specify the latent equation as:

$$
\Pi^{*}{ }_{i j}=\beta_{3}^{\prime} X_{i j}+\varepsilon_{i j}
$$

where $\beta_{3}^{\prime}$ is a vector of coefficients and $\varepsilon_{i j}$ is the disturbance term in the size of the issue equation. The sample selection problem arises in the size of issue equation because the sample contains farmers that were aware of climate change and those that were not aware. Those that were aware choose between adaptation and non-adaptation.

The size of farmers who choose to adapt $\left(\prod_{\mathrm{ij}}, \mathrm{j}=\mathrm{A}\right)$ is observed only if the farmer was aware of climate change and chose to adapt. The size of non-adaptation farmers $\left(\prod_{\mathrm{ij}}, \mathrm{j}=\mathrm{N}\right)$ is observed only if the farmer was aware of climate change and chose not to adapt. These two selection processes can be considered as non-random and the model should explicitly consider this selection in order to produce unbiased estimates. To address the multiple sample selection problems inherent in the size of the adaptation equation, the following model was specified.

Let $\mathrm{Y}^{*}{ }_{\mathrm{i} 1}$ represent the propensity of a farmer being aware of climate change rather than not. Then the relationship between the observed outcome $y_{1 i}$ and the response propensity can be written as:

$$
y_{i 1}=\left\{\begin{array}{ccc}
0 & \ldots \ldots . i f \ldots . Y_{i 1}^{*} . & . . \leq 0 \\
1 & \ldots \ldots . . . i f \ldots . . Y_{i 1}^{*} \ldots . & . \geq 0
\end{array}\right\} \quad \text { Awareness selection }
$$

Let $y_{2 i}$ be the corresponding propensity to choose adaptation measures versus non-adaptation measures as a result of awareness of climate change. This variable is only observed when $y_{1 i}=1$, i.e. $y_{2 i}$ is a choice between adaptation and non-adaptation if the farmer was aware of climate change and takes the value of 1 for adaptation and 0 for non-adaptation.

$$
y_{i 2}\left\{\begin{array}{ccc}
0 & \ldots \ldots i f \ldots . Y_{i 2}^{*} \ldots & . \leq 0 \\
1 & \ldots \ldots . . i f \ldots . Y_{i 2}^{*} \ldots & . . \pm 0
\end{array}\right\} \quad \text { Adaptation selection }
$$

The variable $\prod_{i A}$ is only observed when $\mathrm{y}_{1 \mathrm{i}}=1$ and $\mathrm{y}_{2 \mathrm{i}}=1$ (aware and adaptation), while $\prod_{i N}$ is only observed when $\mathrm{y}_{1 \mathrm{i}}=1$ and $\mathrm{y}_{2 \mathrm{i}}=0$ (aware but not adapt).

Now consider a random sample of $N$ observations. The selectivity model with bivariate probit selection equations for the farmer $i$ are can be specified as:

$$
y_{i 1}=\beta_{1}^{\prime} X_{i 1}+\mu_{i 1}, y_{i 1}=\left\{\begin{array}{ll}
1 & \ldots . . . i f \ldots . . . Y_{i 1}^{*}>0 \\
0 & \ldots . . \text { otherwise }
\end{array} \quad\right. \text { Awareness equation }
$$




$$
\begin{aligned}
& y_{i 1}=\beta_{1}^{\prime} X_{i 1}+\mu_{i 2}, y_{i 1}=\left\{\begin{array}{ll}
1 & \ldots . . i f \ldots . . . Y_{i 1}^{*}>0 \\
0 & \ldots . . \text { otherwise }
\end{array} \quad\right. \text { Adaptation equation } \\
& \Pi_{i j}=\beta_{3}^{\prime} X_{i j}+\varepsilon_{i j}\left\{\begin{array}{l}
E\left(\Pi_{i A} \mid X_{i D}, y_{2}=1, y_{1}=1\right) \\
E\left(\Pi_{i N} \mid X_{i A}, y_{2}=0, y_{1}=1\right)
\end{array}\right.
\end{aligned}
$$

Equations (4) summarises the first situation stage function between awareness and no awareness of climate change and equation (5) between adaptation and no adaptation. The two equations represent a partially observed bivariate probit model. The partially observed situation in the model is due to the unobserved cases of the decision of some farmers between adaptation and non adaptation in cases where farmers were not aware of climate change during the study period.

The conditional distribution of the error terms $\mu_{1}, \mu_{2}$ and $\varepsilon_{i j}$ are distributed according to the multi-normal distribution with zero means and, for identification purposes, the variances equal to 1 , i.e. $\left(\sigma_{\varepsilon}^{2}=\sigma_{\mu 1}^{2}=\sigma_{\mu 2}^{2}=1\right)$ and correlation coefficients $\rho_{12}, \rho_{1 \varepsilon}, \rho_{2 \varepsilon}$, respectively.

The multi-nomial structure of the model leads to the following variance-covariance matrix:

$$
\sum=\left(\begin{array}{ccc}
\sigma_{1}^{2} & \rho_{12} & \rho_{1 \varepsilon} \\
\rho_{12} & \sigma_{2}^{2} & \rho_{2 \varepsilon} \\
\rho_{1 \varepsilon} & \rho_{2 \varepsilon} & \sigma_{\varepsilon}^{2}
\end{array}\right)
$$

The three categories of observations are made with unconditional probabilities as follows:

$$
y=\left(\begin{array}{ll}
1, y_{12}=1: \operatorname{Pr} o b\left(y_{i 1}=1, y_{i 2}=1\right) & =\Phi_{2}\left[\beta_{1}^{\prime} X_{i 1}, \beta_{2}^{\prime} X_{12}, \rho_{12}\right] \\
1, y_{i 2}=0: \operatorname{Pr} o b\left(y=0, y_{i 2}=0\right) & =\Phi_{2}\left[\beta_{1}^{\prime} X_{i 1}-\beta_{2}^{\prime} X_{i 2}-\rho_{12}\right] \\
0, \quad: \operatorname{Pr} o b\left(y_{i 1}=0\right) & =\Phi\left[-\beta_{1}^{\prime} X_{i 1}\right]
\end{array}\right.
$$

The conditional probabilities for a generic $X$ that might appear in either index function can be written as:

$$
\begin{aligned}
& \frac{\partial \operatorname{Pr} o b\left(y_{i 1}=1, y_{i 2}=1\right)}{\partial X_{i}}=\psi_{i 1} \beta_{1}+\psi_{i 2} \beta_{2} \\
& \psi_{i 1}=\phi\left(\beta_{1}^{\prime} X_{i 1}\right) \Phi_{2}\left(\frac{\beta_{2}^{\prime} X_{i 2}-\rho_{12} \beta_{1}^{\prime} X_{i 1}}{\sqrt{1-\rho_{12}^{2}}}\right) \\
& \psi_{i 2}=\phi\left(\beta_{2}^{\prime} X_{i 2}\right) \Phi_{2}\left(\frac{\beta_{1}^{\prime} X_{i 1}-\rho_{12} \beta_{2}^{\prime} X_{i 2}}{\sqrt{1-\rho_{12}^{2}}}\right)
\end{aligned}
$$

Where $\Phi_{2}$ the bivariate is normal cumulative distribution function, $\Phi$ is the univariate normal cumulative distribution function and $\phi$ is the normal distribution function.

The term $\beta_{1}$ is zero if $X_{i}$ does not appear in $X_{i l}$; likewise, $\beta_{2}$ is zero if $X_{i}$ does not appear in $X_{i 2}$. Thus:

$$
\begin{aligned}
E\left(y_{i 2} \mid X_{i 1}, X_{i 2}, y_{i 1}=1\right) & =\operatorname{Pr} o b\left(y_{i 2}=1 \mid X_{i 1}, X_{i 2}, y_{i 1}=1\right) \\
& =\frac{\Phi_{2}\left(\beta_{1}^{\prime} X_{i 2}, \rho_{12}\right)}{\Phi\left(-\beta_{1}^{\prime} X_{i 1}\right)}
\end{aligned}
$$


and

$$
\frac{\delta E\left(y_{i 2} \mid X_{i 1}, X_{i 2}, y_{i 1}=1\right)}{\delta X_{i}}=\frac{\psi_{i 1} \beta_{1}+\psi_{i 2} \beta_{2}}{\Phi\left(-\beta_{1}^{\prime} X_{i 1}\right)}-\frac{\Phi_{2}\left(\beta_{1}^{\prime}, \beta_{2}^{\prime} X_{i 2}, \rho_{12}\right) \phi\left(\beta_{1}^{\prime} X_{i 1}\right) \beta_{1}}{\left[\Phi\left(-\beta_{1}^{\prime} X_{i 1}\right)\right]^{2}}
$$

According to Heckman (1979) the corresponding log-likelihood function to be maximized with respect to the parameters $\beta_{1}^{\prime}, \beta_{2}^{\prime}$ and $\rho_{12}$ can be derived as:

$$
\Omega=\sum_{y_{i 1}=1, y_{i 2}=1} \operatorname{In} \Phi_{2}\left(\beta_{1}^{\prime} X_{i 1}, \beta_{2}^{\prime} X_{i 2}, \rho_{12}\right)+\sum_{y_{i 1}=1, y_{i 2}=0} \Phi_{2}\left(\beta_{1}^{\prime} X_{i 1},-\beta_{2}^{\prime} X_{i 2}, \rho_{12}\right)+\sum_{y_{11}=0} \Phi\left(-\beta_{1}^{\prime} X_{i 1}\right)
$$

A natural starting point for estimation would be an extension of Heckman's two-step estimator. In the first step, equation (4) and (5) are estimated using a Bivariate Probit Model (BPM) to obtain the two selectivity bias terms $\lambda_{i 1}$ and $\lambda_{i 2}$ (the inverse Mill's ratio); which are defined as (Greene, 2003):

$$
\begin{aligned}
& \lambda_{i 1}=\phi\left(\beta_{1}^{\prime} X_{i 1}\right)\left(\frac{\Phi\left[\beta_{2}^{\prime} X_{i 2}-\beta_{1}^{\prime} X_{i 1} \rho_{12}\right] / \sqrt{1-\rho_{12}^{2}}}{\Phi_{2}\left[\beta_{1}^{\prime} X_{i 1}, \beta_{2}^{\prime} X_{i 2}, \rho_{12}\right]}\right) \quad \text { if } \quad y_{1}=1 \\
& \lambda_{i 2, A}=\phi\left(\beta_{2}^{\prime} X_{i 2}\right)\left(\frac{\Phi\left[\beta_{1}^{\prime} X_{i 1}-\beta_{2}^{\prime} X_{i 2} \rho_{12}\right] / \sqrt{1-\rho_{12}^{2}}}{\Phi_{2}\left[\beta_{1}^{\prime} X_{i 1}, \beta_{2}^{\prime} X_{i 2}, \rho_{12}\right]}\right) \quad \text { if } \quad y_{2}=1 \\
& \lambda_{i 2, N}=\phi\left(-\beta_{2}^{\prime} X_{i 2}\right)\left(\frac{\Phi\left[\beta_{1}^{\prime} X_{i 1}-\beta_{2}^{\prime} X_{i 2} \rho_{12}\right] / \sqrt{1-\rho_{12}^{2}}}{\Phi_{2}\left[-\beta_{1}^{\prime} X_{i 1}, \beta_{2}^{\prime} X_{i 2}, \rho_{12}\right]}\right) \quad \text { if } \quad y_{2}=0
\end{aligned}
$$

The BPM utilises maximum likelihood estimation (MLE) method to allow the stochastic error terms to be correlated across equations. The parameter $\rho_{12}$ estimates the correlation between the error terms of the BPM equations (4) and (5). If the MLE estimate of the correlation coefficient $\rho_{12}$ is significant, then the BPM estimation is more efficient than that of independent Probit equations.

Finally, the sample selectivity adjusted size of issue equation can be written as:

$$
E\left(\Pi_{i A} \mid X_{i A}, y_{2}=1, y_{1}=1\right)=\beta_{3}^{\prime} X_{i A}+\gamma_{1} \lambda_{i 1}=\gamma_{2} \lambda_{i 2 A}+\varepsilon_{A}^{*}
$$

Where $\varepsilon_{A}^{*}=\varepsilon_{i A}-\gamma_{1} \lambda_{i 1}-\gamma_{2} \lambda_{i 2, A} \quad E\left(\varepsilon^{*} \mid y_{2}=1, y_{1}=1\right)=0$

$$
E\left(\Pi_{i N} \mid X_{i N}, y_{2}=0, y_{1}=1\right)=\beta_{4}^{\prime} X_{i N}+\gamma_{1} \lambda_{i 1}=\gamma_{2} \lambda_{i 2 N}+\varepsilon_{N}^{*}
$$

Where $\varepsilon_{N}^{*}=\varepsilon_{i N}-\gamma_{1} \lambda_{i 1}-\gamma_{2} \lambda_{i 2, N}$

$$
E\left(\varepsilon^{*} \mid y_{2}=0, y_{1}=1\right)=0
$$

In the second estimation stage (adaptation), the Tobit issue size equations incorporate the probability of the limit and non-limit observations from the first stage (awareness) estimation and take into account the correlation across equations. The correlation could arise because the unobservable capture might be correlated with the unobservable that influence the choice of the form of awareness (Yes or No) i.e. the correlation coefficients from equations (4) and (6) and equations (5) and (6) might not equal zero. The Heckman estimators described above are considered consistent, even though not fully efficient. To account for the possible correlation between the three error terms, the model was estimated in one step i.e. fully simultaneously using Full Information Maximum Likelihood (FIML) techniques. In contrast to the two-step procedure, such technique was considered to produce consistent and fully efficient estimates.

\section{Results}

The results are presented as descriptive statistics for awareness in Table 1 and descriptive statistics for decisions to adapt or not to adapt to climate change in Table 2. The different types of adaptation measures chosen by livestock farmers are highlighted in Table 3 for the livestock farmers who were aware and those who were aware 
and decided to adapt. This is followed by results of Heckman probit selection model that are presented in Table 4.

Tablelpresents data about livestock farmers' awareness of climate change. Of importance to the study were the groups of variables with highest percentages. The results indicated that $57 \%$ of a total of 250 livestock farmers were more aware of climate change and $43 \%$ were not aware during the study period. With reference to household size group (6-10), the percentages were, aware (60.10\%), not aware (53.30\%). With gender $93.70 \%$ represented males who were aware of climate change and $83.20 \%$ were males who were not aware of climate change. The age group of 51-70 years represented the group with the highest frequency. In this group $65.80 \%$ were aware of climate change compared with $56.00 \%$ who were not aware of climate change. From the results $90.90 \%$ were married people who were aware of climate change and $84.10 \%$ were not aware. Standard 6 level of education appeared to be the group with the highest percentage. In this group $41.30 \%$ were aware compared with $42.10 \%$ who were not aware. Among the livestock farmers who owned 1-100 cattle and sheep $64.50 \%$ were aware of climate change as opposed to $39.30 \%$ who were not aware. Surprisingly, $72.70 \%$ of farmers who had no access to formal extension services were aware and $72.90 \%$ were not aware.

Furthermore, from those livestock farmers who were aware of climate change $74.80 \%$ indicated that they did not benefit from information about climate change in terms of livestock improvement, and among those that were not aware $78.50 \%$ did not benefit. From those who were aware $55.90 \%$ perceived an increase in temperatures and from those who were not aware $72.00 \%$ perceived an increase in temperatures. From those who were aware $74.10 \%$ perceived a decrease in rainfall whereas $91.60 \%$ from those who were not aware perceived a decrease in rainfall. A high percentage of those who were aware and those who were not aware acquired land through inheritance with a frequency of $61.50 \%$ and $33.60 \%$ respectively.

Similarly, Table 2 presents descriptive statistics of livestock farmers who were aware of climate change and decided to select some adaptation measures. Among 143 livestock farmers who were aware of climate change $71 \%$ selected some adaption measures as presented in Table 2, and 29\% did not. With reference to household size group (6-10), the percentages were, adapted (58.40\%), did not adapt (64.30\%). With regard to gender, $96.00 \%$ represented those male livestock farmers who adapted to climate change and $88.10 \%$ were those who did not. The age group of 51-70 years represented the group of livestock farmers with the highest percentage. In this group $66.30 \%$ adapted and $64.30 \%$ did not. The results from Table 2 also indicated that $90.10 \%$ of livestock farmers were those married farmers who adapted to climate change and $92.90 \%$ did not adapt. Standard 6 level of education appeared to be the group with the highest percentage. In this group $40.60 \%$ adapted compared with $42.90 \%$ who did not. Among those livestock farmers who owned 1-100 cattle and sheep, $64.00 \%$ adapted to climate change as opposed to $23.80 \%$ who did not adapt. Out of the total of 101 livestock farmers who adapted, $63.40 \%$ had no access to formal extension services while out of the total of 42 livestock farmers, $92.50 \%$ had access.

From those livestock farmers who adapted to climate change $69.30 \%$ indicated that they did not benefit from information about climate change in terms of livestock improvement, and among those who did not adapt $88.10 \%$ did not benefit. From those who adapted $50.50 \%$ perceived an increase in temperatures compared with $69.00 \%$ who perceived an increase in temperature but did not adapt. From those who adapted, $75.20 \%$ perceived a decrease in rainfall whereas $71.40 \%$ were those who perceived a decrease but did not adapt. A high percentage of those who adapted and those who did not adapt did not own land. The percentages were $32.70 \%$ and $52.40 \%$ respectively.

Table 3 presents percentages of adaptation measures selected by livestock farmers who were aware of climate change and those who were aware and adapted to climate change. For those livestock farmers who were only aware of climate and those who were aware and adapted, dipping and dosing were prominent adaptation measures. The percentages were $38.5 \%$ and $38.7 \%$ respectively. The least common adaptation measure was exchange of livestock for the two groups. A study by Imai (2003) confirmed that livestock farmers in rural Kenya used livestock as liquid assets. Other adaptation measures were selected at different percentage levels.

The results of the Heckman probit model were presented in Table 4. The results indicated that the model had good overall predictive power, as indicated by the overall $76.0 \%$ prediction for the selection model and $71.4 \%$ for the outcome model. The likelihood ratio $\chi^{2}$ - test was 237.107 for selection model and 182.905 for the outcome model. The likelihood ratio $\chi^{2}$ - tests were used to test the null hypothesis for each of the model that all coefficients were zero. Given the $p$-value of 0.01 for both the $\chi^{2}$-tests, the null hypothesis for each model was rejected. The results from the selection model, which predicted factors that affected awareness to climate change, indicated that marital status, level of education, formal extension, temperatures and the way in which land used 
for farming was acquired, significantly affected awareness of climate change. Variables that significantly affected adaptation were: gender, formal extension, information received about climate change to improve livestock production, temperatures and the way in which land was acquired.

\section{Discussion}

The significant variables in the prediction of awareness and adaptation were gender, marital status, education, formal extension, information on climate change that improved livestock production, temperatures, and also the way in which land for farming was acquired. Gender had no significant effect on awareness but on adaptation to climate change. The study showed that male farmers were more responsive to adaptation measures (Table 4). A similar study that was conducted by Bayard et al. (2007) discovered that male farmers were more responsive to adaptation to environmental degradation by planting alley crops in Haiti. Other similar studies conducted by Hassan and Nhemachena (2008), Deressa et al. (2009) and Deressa et al. (2010) indicated that males were more responsive to adapting to climate change. The married livestock farmers were more aware (Table 1) and adapted to climate change (Table 2). The possible reason was that those livestock farmers interviewed had families who had stayed in the area of study for a reasonable amount of time to observe climate change.

The group with standard 6 level of education showed more awareness (Table 1) and adaptation (Table 2) to climate change. Level of education significantly but negatively affected awareness to climate change and did not have any significant effect on adaptation (Table 4). The results indicated that education did not have a positive contribution to awareness. Although livestock farmers in the area of study adapted to climate change, education appeared not to be the contributing factor to adaptation. Previous research (Bayard et al., 2007) indicated similar results whereby education significantly but negatively affected awareness to climate change. A study by Kabubo-Mariara (2008) discovered that education was negatively correlated with adaptation to sheep and goats rearing. The reason given was that educated farmers had alternative income earning opportunities. This is in contrary to a study by Apata et al. (2009) which indicated that education influenced adaptation positively. Besides, the study by Deressa et al. (2009) and Deressa et al. (2010) indicated similar results that education of head of household increased the probability of adapting to climate change.

A high percentage $(72.70 \%)$ in the whole sample did not receive formal extension services and information on livestock $(74.80 \%)$. Even from those who adapted to climate change, a small percentage $(36.60 \%)$ received formal extension services and $30.70 \%$ received information about climate change. Formal extension positively and significantly affected awareness to climate change and adaptation. The more the farmers had access to extension services and information about climate change, the more they adapted to climate change (Luseno, et al. 2003). Formal extension must have played a role in informing livestock farmers about climate change. Formal extension service by government seemed to be a good tool that could be used to increase awareness about climate change to livestock farmers in the study area. Similar research conducted by Hassan and Nhemachena (2008), Apata et al., (2009), Deressa et al., (2010) and Bryan et al., (2009) indicated that access to extension services had a strong positive influence on adapting to climate change. Similar research conducted by D'Emden et al. (2008) indicated that extension attendance had significant effect on adoption of conservation tillage in the cropping regions of Australia. Chen et al., (2010) also iterated that information sharing on perception about climate change led to adaptation in China and the results proved that the farmer's perceptions were correct.

Access to information about climate change positively and significantly affected adaptation although it did not have a significant effect on awareness. The results showed that media played an important role in informing livestock farmers about climate change as this has increased the tendency of adapting to climate change (Kandlinkar and Risbey, 2000). A study by Deressa et al. (2009) discovered that information on climate change increased adaptation. Farmers used different crop varieties to reduce risk. A high percentage of livestock farmers (aware and not aware) were of the opinion that there was increase in temperatures during the study period (Table 1). Those who adapted also saw an increase in temperatures (Table 2). Changes in temperatures had significant but negative effect on awareness to climate change and adaptation thereof. Changes in temperatures did not affect adaptation to climate change. On the contrary, in the study conducted by Kabubo-Mariara (2008), farmers in Kenya would reduce their livestock to reduce risks and minimise losses when temperatures increased. Again a study conducted by Galvin et al. (2002) indicated that livestock owners would move their livestock in areas with high climate variability. Hassan and Nhemachena (2008) also indicated that farmers shifted away from mono-cropping and irrigated as a way of adapting to climate change during changes in temperatures. A similar study that was conducted by Apata et al. (2009) indicated that temperatures positively affected adaptation to climate change. Finally, livestock farmers who did not own land had high frequency of adaptation measures although it was the same group that was aware and got land through inheritance. The way in which land was acquired significantly and positively affected climate change awareness and adaptation. Both livestock farmers 
who were aware and those who were aware and adapted, acquired land through inheritance (Kabubo-Mariana, 2005).

\section{Summary and conclusion}

This paper investigated the extent of awareness of climate change by cattle and sheep farmers in the Eastern Cape Province of South Africa. It further explored adaptation measures that they followed and factors that affected adaption measures. The study was based on a cross-sectional household survey data collected from 250 respondents of 500 households during the 2005-2009 farming season. The Heckman's two step model was used to determine factors that affected awareness and adaptation of livestock farmers to climate change. The results from the selection model, which predicted factors that affected awareness to climate change, indicated that marital status, formal extension and the way in which land used for farming was acquired, significantly affected awareness of climate change. Level of education and temperatures affected awareness significantly but negatively. The results from the adaptation model indicated that the variables that significantly affected adaptation were: gender, information received about climate change to improve livestock production, and the way in which land was acquired. Formal extension and temperatures significantly affected adaptation but negatively. The study suggests that the positive and significant variables that affected awareness and adaptation which were married livestock farmers, formal extension, the way in which land was acquired, gender, information on climate change to improve livestock production, be considered when adaptation strategies are implemented. It further suggests that government awareness programmes about climate change awareness should focus more on married livestock farmers as they were more responsive. It further suggests the need to provide timely and appropriate information on climate change through extension programmes. The fact that the way in which land that was acquired was positive and significant in both selection and adaptation models indicate its effective role in creating awareness and adaptation to climate change. Gender which positively and significantly affected adaptation suggested selection of adaptation strategies depends on males possibly because they are the ones who make decisions in the household farming activities. Finally, information on climate change to improve livestock production appeared to play a significant role in the selection of adaptation measures. This calls for timely and relevant information on climate change to be made available to livestock farmers.

\section{References}

Apata, T.G., Samuel, K.D., and Adeola, A.O. (2009). Analysis of climate change perception and adaptation among arable food crop farmers in South West Nigeria. Contributed paper prepared for presentation at International Association of Agricultural Economists’ 2009 conference, Beijing, China.

Bayard, B., Jolly C.M., and Shannon, D.A. (2007). The economics of adoption and management of alley cropping in Haiti. Journal of Environmental Management, Vol 85:62-70. doi:10.1016/j.jenvman.2006.05.001, http://dx.doi.org/10.1016/j.jenvman.2006.05.001

Bryan, E., Deressa, T.T., Gbetibouo, G.A and Ringler, C. (2009). Adaptation to climate change in Ethiopia and South Africa: options and constraints. Environmental Science and Policy, Vol 12:413-426. doi:10.1016/j.envsci.2008.11.002, http://dx.doi.org/10.1016/j.envsci.2008.11.002

Chen Li, Zuo, Ting and Rasaily, R.G. (2010). Farmers' adaptation to climate risk in the context of China. A research on Jianghan Plain of Yangste River Basin. Agriculture and Agricultural Science Procedia, Vol 1 : 116-125. doi:10.1016/j.aaspro.2010.09.014, http://dx.doi.org/10.1016/j.aaspro.2010.09.014

D’Emden, F., Llewellyn, R. S., and Burton, M.P. (2008). Factors affecting adoption of conservation tillage in Australian cropping regions. The Australian Journal of Agricultural and Resource Economics, Vol 52: 169-182. doi:10.1111/j.1467-8489.2008.00409.x, http://dx.doi.org/10.1111/j.1467-8489.2008.00409.x

Deressa, T.T., Hassan R.N., Ringler C, Alemu, T and Yesuf, M. (2009). Determinants of farmers' choice of adaptation methods to climate change in the Nile Basin of Ethiopia. Global Environmental Change, Vol 19:248-255. doi:10.1016/j.gloenvcha.2009.01.002, http://dx.doi.org/10.1016/j.gloenvcha.2009.01.002

Deressa, T.T.; Hassan R.N. and Ringler C. (2010). Perception and adaptation to climate change to climate change in the Nile Basin of Ethiopia. Journal of Agricultural Science, Cambridge University Press pages 1-9.

Fischer, G., Shah, M., Francesco, N. and Van Velhuizen, H. (2005). Socio-economic and climate change impacts on agriculture: an integrated assessment, 1990-2080. Philosophical Transactions of the Royal Society, B 2005 360, 2067- 2083.

Greene, W.H. (2003). Econometric analysis. Fifth edition. Prentice Hall, New Jersey. 
Galvin, K.A., Boone, R.B., Smith, N.M., Lynn, S.J. (2001). Impacts of climate variability on East African pastoralists: Linking social science and remote sensing. Climate Research, 19(1), 161-172. doi:10.3354/cr019161, http://dx.doi.org/10.3354/cr019161

Gbetibouo, G., Hassan, R. (2005). Economic impact of climate change on major South African field crops: A Ricardian approach. Global and Planetary Change, 47: 143-152. doi:10.1016/j.gloplacha.2004.10.009, http://dx.doi.org/10.1016/j.gloplacha.2004.10.009

Hassan, R and Nhemachena, C. (2008). Determinants of African farmers' strategies for adaptation to climate change: Multinomial choice analysis. African Journal of Agricultural and Resource Economics, Vol 2 No. $1: 83-104$.

Heckman, J.J. (1979). Sample Selection Bias as a Specification Error. Econometrica, Vol 47; 153-161. doi:10.2307/1912352, http://dx.doi.org/10.2307/1912352

Imai, K. (2003). Is livestock important for risk behaviour and activity choice in rural households? Evidence from Kenya. Journal of African Economies, 12: 271-295. doi:10.1093/jae/12.2.271, http://dx.doi.org/10.1093/jae/12.2.271

Kabubo-Mariara, J. (2008). Climate change adaptation and livestock activity choices in Kenya: An economic analysis. Natural Resource Forum, Vol 32; 131-141. doi:10.1111/j.1477-8947.2008.00178.x, http://dx.doi.org/10.1111/j.1477-8947.2008.00178.x

Kabubo-Mariara, J. (2007). Poverty and rural livelihoods in Kenya: Evidence from a

Semi-arid region. In: Tisdell, C. (Ed.) Poverty, Poverty Alleviation and Social Disadvantage: Analysis, Case Studies and Policies. Serials Publications, Vol III, Part VII, Chapter 56.

Kandlinkar, M and Risbey, J. (2000). Agricultural impacts of climate change: If adaptation is the answer, what is the question? Climatic Change, Vol 45:529-39. doi:10.1023/A:1005546716266, http://dx.doi.org/10.1023/A:1005546716266

Luseno, W.K., Mcpeak, J.G., Barrett, C.B., Little, D., Gebru, G. (2003). Assessing the value of climate forecast information for pastoralists: Evidence from Southern Ethiopia and Northern Kenya. World Development, 31(9): 1477-1494. doi:10.1016/S0305-750X(03)00113-X, http://dx.doi.org/10.1016/S0305-750X(03)00113-X

Turpie, J, Wrinkler, H., Spalding-Fecher, R. and Midgley, G. (2002). Economic impacts of climate change in South Africa: A preliminary analysis of unmitigated damage costs. Southern Waters Ecological Research and Consulting and Energy and Development Research Centre, University of Cape Town, Research paper, 1-56.

Yesuf, M., Di Falco, S., Deressa, T., Ringler, C. and Kohlin, G. (2008). The impact of climate change and adaptation on food production in Low income countries. Evidence from the Nile basin, Ethiopia. IFPRI Discussion Paper 00828, December 2008. 
Table 1. Descriptive statistics (Aware or not aware of climate change)

Dependent variable=Aware of climate change (dummy: takes the value of 1 if aware and 2 if not aware): $\mathrm{N}=250$

\begin{tabular}{|c|c|c|}
\hline \multirow{2}{*}{ Description of variables } & Aware $\mathrm{N}_{1}=147(57 \%)$ & Not aware $\mathrm{N}_{2}=107(43 \%)$ \\
\hline & $(\%)$ & $(\%)$ \\
\hline \multicolumn{3}{|l|}{ Size (size) } \\
\hline $1-5$ & 18.90 & 29.00 \\
\hline $6-10$ & 60.10 & 53.30 \\
\hline $11=15$ & 19.60 & 17.80 \\
\hline $16-20$ & 1.40 & \\
\hline \multicolumn{3}{|l|}{ Gender (Gen) } \\
\hline $1=$ Male & 93.70 & 83.20 \\
\hline $2=$ Female & 6.30 & 16.80 \\
\hline \multicolumn{3}{|l|}{ Age group (Age) } \\
\hline $20-30$ & 1.40 & 4.70 \\
\hline $31-40$ & 5.60 & 5.60 \\
\hline $41-50$ & 16.80 & 13.10 \\
\hline $51-70$ & 65.80 & 56.00 \\
\hline $71-80+$ & 10.50 & 20.60 \\
\hline \multicolumn{3}{|l|}{ Marital status (Mar) } \\
\hline $1=$ Single & 4.90 & 10. \\
\hline $2=$ Married & 90.90 & 84.10 \\
\hline 4=Widowed & 3.50 & 0.90 \\
\hline $5=$ Separated & 0.70 & 4.70 \\
\hline \multicolumn{3}{|l|}{ Educational status (Educ) } \\
\hline $1=$ Pre School & 0.70 & 0.90 \\
\hline $2=$ Standard 4 & 14.00 & 23.40 \\
\hline $3=\operatorname{Std} 6$ & 41.30 & 42.10 \\
\hline $4=\operatorname{Std} 10$ & 26.60 & 9.30 \\
\hline $5=$ Higher & 7.70 & 5.60 \\
\hline $6=$ None & 9.80 & 18.70 \\
\hline \multicolumn{3}{|c|}{ Total cattle and sheep owned: $2005-2005$ (Total) } \\
\hline $1-100$ & 64.50 & 39.30 \\
\hline $101-200$ & 21.50 & 47.70 \\
\hline $201-300$ & 4.70 & 7.50 \\
\hline $301-400$ & 5.60 & 2.80 \\
\hline $401-500+$ & 3.70 & 1.80 \\
\hline \multicolumn{3}{|l|}{ Formal extension services access (Exten) } \\
\hline $1=$ Yes & 27.30 & 27.10 \\
\hline $2=\mathrm{No}$ & 72.70 & 72.90 \\
\hline \multicolumn{3}{|l|}{ Information on livestock (Infstock) } \\
\hline $1=$ Yes & 23.80 & 13.10 \\
\hline $2=\mathrm{No}$ & 74.80 & 78.50 \\
\hline \multicolumn{3}{|l|}{ Aware of drought (Awaredr) } \\
\hline $1=$ Yes & 100.00 & 100.00 \\
\hline $2=\mathrm{No}$ & 00.00 & 00.00 \\
\hline \multicolumn{3}{|l|}{ Temperature perceptions (Temps) } \\
\hline $1=$ Increased & 55.90 & 72.00 \\
\hline $2=$ Decreased & 16.10 & 17.80 \\
\hline $3=$ Same & 0.70 & 2.80 \\
\hline $4=$ Not observed any changes & 6.30 & 0.90 \\
\hline 5=Unpredictable & 21.00 & 6.50 \\
\hline \multicolumn{3}{|l|}{ Rains perception: 2005-2009 (Rains) } \\
\hline $1=$ Increased & 2.10 & 1.90 \\
\hline $2=$ Decreased & 74.10 & 91.60 \\
\hline $3=$ Same & 3.50 & 0.90 \\
\hline $4=$ Floods & 0.70 & 0.00 \\
\hline $5=$ Not observed any changes & 1.40 & 0.00 \\
\hline Erratic & 18.20 & 5.60 \\
\hline \multicolumn{3}{|l|}{ How acquired land (Howacq) } \\
\hline $1=0 w n$ finance & 15.50 & 16.80 \\
\hline $2=$ Bond & 0.00 & 0.90 \\
\hline $3=$ Land reform & 32.20 & 4.70 \\
\hline $6=$ Inheritance & 61.50 & 33.60 \\
\hline $7=$ Not applicable & 38.50 & 43.90 \\
\hline
\end{tabular}


Table 2. Descriptive statistics (Decisions to adapt or not to adapt)

\begin{tabular}{|c|c|c|}
\hline \multicolumn{3}{|c|}{ Dependent variable=Adaptation to climate change (dummy: takes the value of 1 if adapted and 2 if did not adapt): $N=143$} \\
\hline Description of variables & Adapt $\mathrm{N}_{1}=101(71 \%)$ & Not Adapt $\mathrm{N}_{2}=42(29 \%)$ \\
\hline & $(\%)$ & $(\%)$ \\
\hline \multicolumn{3}{|l|}{ Size (size) } \\
\hline $1-5$ & 17.80 & 21.40 \\
\hline $6-10$ & 58.40 & 64.30 \\
\hline $11=15$ & 22.80 & 11.90 \\
\hline $16-20$ & 1.00 & 2.40 \\
\hline \multicolumn{3}{|l|}{ Gender (Gen) } \\
\hline $1=$ Male & 96.00 & 88.10 \\
\hline $2=$ Female & 4.00 & 11.90 \\
\hline \multicolumn{3}{|l|}{ Age group (Age) } \\
\hline $20-30$ & 2.00 & 0.00 \\
\hline $31-40$ & 7.90 & 0.00 \\
\hline $41-50$ & 14.90 & 21.40 \\
\hline $51-70$ & 66.30 & 64.30 \\
\hline $71-80+$ & 8.90 & 14.30 \\
\hline \multicolumn{3}{|l|}{ Marital status (Mar) } \\
\hline $1=$ Single & 6.90 & 0.00 \\
\hline $2=$ Married & 90.10 & 92.90 \\
\hline 4=Widowed & 3.00 & 4.80 \\
\hline $5=$ Separated & 0.00 & 2.40 \\
\hline \multicolumn{3}{|l|}{ Educational status $(E d u c)$} \\
\hline 1=Pre School & 0.00 & 2.40 \\
\hline $2=$ Standard 4 & 10.90 & 21.40 \\
\hline $3=$ Std 6 & 40.60 & 42.90 \\
\hline $4=\operatorname{Std} 10$ & 29.70 & 19.00 \\
\hline $5=$ Higher & 10.90 & 0.00 \\
\hline $6=$ None & 7.90 & 14.30 \\
\hline \multicolumn{3}{|c|}{ Total cattle and sheep owned: $2005-2005$ (Total) } \\
\hline $1-100.1 .1 .1$ & 64.00 & 23.80 \\
\hline $101-200$ & 22.70 & 50.00 \\
\hline $201-300$ & 2.70 & 14.30 \\
\hline $301-400$ & 6.70 & 7.10 \\
\hline $401-500+$ & 4.00 & 4.80 \\
\hline \multicolumn{3}{|l|}{ Formal extension services access (Exten) } \\
\hline $1=$ Yes & 36.60 & 4.80 \\
\hline $2=\mathrm{No}$ & 63.40 & 92.50 \\
\hline \multicolumn{3}{|l|}{ Information on livestock (Infstock) } \\
\hline $1=$ Yes & 30.70 & 7.10 \\
\hline $2=\mathrm{No}$ & 69.30 & 88.10 \\
\hline $3=$ Not applicable & 0.00 & 4.80 \\
\hline \multicolumn{3}{|l|}{ Aware of drought (Awaredr) } \\
\hline $1=$ Yes & 100.00 & 90.50 \\
\hline $2=\mathrm{No}$ & 0.00 & 9.50 \\
\hline \multicolumn{3}{|l|}{ Temperature perceptions (Temps) } \\
\hline $1=$ Increased & 50.50 & 69.00 \\
\hline $2=$ Decreased & 16.80 & 14.30 \\
\hline $3=$ Same & 4.00 & 14.30 \\
\hline $4=$ Unpredictable & 28.70 & 2.40 \\
\hline \multicolumn{3}{|l|}{ Rains perception: 2005-2009 (Rains) } \\
\hline $1=$ Increased & 2.00 & 2.40 \\
\hline $2=$ Decreased & 75.20 & 71.40 \\
\hline $3=$ Same & 2.00 & 7.10 \\
\hline $4=$ Floods & 0.00 & 2.40 \\
\hline $5=$ Not observed any changes & 2.00 & 0.00 \\
\hline $6=$ Erratic & 18.80 & 16.70 \\
\hline \multicolumn{3}{|l|}{ How acquired land (Howacq) } \\
\hline $1=O w n$ finance & 17.80 & 9.50 \\
\hline $2=$ Bond & 0.00 & 0.00 \\
\hline $3=$ Land reform & 22.80 & 2.40 \\
\hline $4=$ Inheritance & 26.70 & 35.70 \\
\hline $5=$ Not applicable & 32.70 & 52.40 \\
\hline
\end{tabular}


Table 3. Adaptation measures

\begin{tabular}{lcc}
\hline & $\begin{array}{c}\text { Aware: } \\
\text { Measures }\left(\mathbf{N}_{\mathbf{1}}=\mathbf{1 4 3}\right)\end{array}$ & $\begin{array}{c}\text { Aware and adapt: Measures }\left(\mathbf{N}_{\mathbf{2}}=\mathbf{1 0 1}\right) \\
\text { \% }\end{array}$ \\
\hline Supplementary feed & 12.60 & 9.90 \\
Dip and Dose & 38.50 & 38.70 \\
Feed supplement & 23.80 & 27.70 \\
Sell stock to buy medicine & 1.40 & 2.00 \\
Exchange stock & 0.70 & 1.00 \\
Fence camps & 4.90 & 6.90 \\
Portable water & 2.10 & 3.00 \\
No adaptation & 14.70 & 10.90 \\
\hline Total & 100.00 & 100.00 \\
\hline
\end{tabular}

Table 4. Results of the Heckman probit selection model

\begin{tabular}{|c|c|c|c|c|c|}
\hline \multicolumn{3}{|c|}{ Awareness: Selection model $\left(\mathrm{N}_{1}=\mathbf{2 5 0}\right)$} & \multicolumn{3}{|c|}{ Adaptation: Outcome model $\left(\mathrm{N}_{2}=143\right)$} \\
\hline & B & Sig & B & & Sig \\
\hline$\overline{\text { Size }}$ & -0.041 & 0.485 & -0.20 & & 0.760 \\
\hline Gen & 0.687 & 0.241 & $1.536^{*}$ & & 0.055 \\
\hline Age & 0.006 & 0.966 & 0.133 & & 0.387 \\
\hline Mar & $0.922 * *$ & 0.015 & -0.382 & & 0.415 \\
\hline Educ & $-0.291 *$ & 0.030 & -0.121 & & 0.432 \\
\hline Total & 0.000 & 0.539 & 0.000 & & 0.616 \\
\hline Formal extens & $3.180 * * *$ & 0.000 & $-0.794^{*}$ & & 0.095 \\
\hline Infstock & -0.657 & 0.193 & $1.520 * * *$ & & 0.004 \\
\hline Awaredr & 0.195 & 0.656 & 0.887 & & 0.119 \\
\hline Temps & $-0.436 * * *$ & 0.001 & $-0.368 * *$ & & 0.014 \\
\hline Rains & -0.047 & 0.721 & -0.110 & & 0.525 \\
\hline Howacq & $0.311 * * *$ & 0.001 & $0.167^{*}$ & & 0.057 \\
\hline Constant & $-7.580 * * *$ & 0.000 & $-3.497^{*}$ & & 0.044 \\
\hline \multicolumn{6}{|l|}{ Classification: } \\
\hline Yes & & $=83.9 \%$ & & $=$ & $84.2 \%$ \\
\hline No & & $=59.8 \%$ & & $=$ & $52.2 \%$ \\
\hline Overall & & $=76.0 \%$ & & $=$ & $71.4 \%$ \\
\hline-2 Log likelihood & & $=237.107(\mathrm{df}=12)$ & & $=$ & $182.905(\mathrm{df}=12)$ \\
\hline$\chi^{2}-$ test & & $=79.270(\mathrm{P}<0.01)$ & & $=$ & $43.064(\mathrm{P}<0.01)$ \\
\hline
\end{tabular}

